\title{
Multicultural Experiential Learning: An Approach to Learning, Developing, and Maintaining Multicultural Skills
}

\author{
Jessica Donley ${ }^{1 *}$ \\ 1 United States \\ *donleyjm@gmail.com
}

Received: 25 January 2018 ; Accepted: 6 March 2018 ; Published: 1 July 2018

Editor: Daphne Rickson Reviewer: Debbie Bates

\begin{abstract}
Multicultural experiential learning is an approach that offers a unique way for music therapy students and professionals to learn, develop, and maintain multicultural skills that are necessary when working with any client. This approach may help music therapists and students, particularly those that identify as White and female in gaining a greater awareness of themselves in relation to diverse clients. Multicultural learning is a process that involves three steps: self-examination, learning about other cultures, and developing clinical skills. Because of the varied experiences and training of music therapists, this approach offers opportunities for music therapists to take initiative in their own multicultural learning. It also provides new developments in university and college curriculums. Examples of multicultural experiential learning and the process of the author and music therapist are discussed to provide insight into how these tasks impacted her and her awareness of multicultural issues.
\end{abstract}

Keywords: music therapy, multicultural, experiential learning, training

\section{Introduction}

There has been an increased interest of multicultural topics in music therapy as seen in conference programs, continuing music therapy education courses, and changing higher education curriculums ( $10^{\text {th }}$ European Music Therapy Conference, 2016; American Music Therapy Association, 2016; Mid-Atlantic Region of the Music Therapy Association, 2017; The World Federation of Music Therapy, 2017a; The World Federation of Music Therapy, 2017b). These topics are being integrated into professional development and training for music therapists and music therapy students at the local, regional, national, and international levels. The 2016 American Music Therapy Association national conference emphasized international and multicultural issues through its theme and conference program, which included the Global Perspectives Session (American Music Therapy Association, 2016). The conference committee continued the Global Perspectives Session in 2017 and is continuing the tradition in this year's conference in November (American Music Therapy Association, 2017; American Music Therapy Association, 2018). The 15th World Congress of Music Therapy in Tsukuba, Japan also hosted presentations on multicultural music therapy, cross-cultural music therapy, and intercultural topics (The World Federation of Music Therapy, 2017b). A cultural pro- 
gram with experiential learning opportunities about Japanese culture relative to the host city was available to attendees (The World Federation of Music Therapy, 2017a).

Some music therapy programs at institutes of higher education have adapted their curriculum to encourage student understanding of other cultures. This creates an encouraging environment for students from underrepresented backgrounds, such as students of indigenous or international cultures to study music therapy, which helps diversify a predominantly White female profession (Mahoney, 2015; Music Therapy at Temple University, n.d.; University of Limerick, n.d.; Victoria University of Wellington, n.d.). Multicultural topics in concurrent sessions (10th European Music Therapy Conference, 2016; American Music Therapy Association, 2016; Hadley \& Norris, 2016; The World Federation of Music Therapy, 2017b), CMTE's, and in the curriculum (Music Therapy at Temple University, n.d.; Slippery Rock University, n.d.; University of Limerick, n.d.; Victoria University of Wellington, n.d.) require an exploration of the identity of the music therapist and other cultures.

Music therapists can explore their cultural identity and the cultures of others using multicultural learning. According to Orozco, Lee, Blando, and Shooshani (2014), multicultural learning contains practicum and internship learning opportunities for counselors working with individuals from diverse cultures. Counselors may have difficulty generalizing explorations of the self and other if the context of professional development and training activities does not include a diversity of people (Bateson, 2000). For instance, some universities are located in rural areas. For this reason, music therapists could struggle to translate what is learned in the classroom or professional development setting to the therapeutic setting. It is unclear if these traditional learning experiences prepare music therapists to meet multicultural needs of clients. Multicultural learning can assist, and is an "ongoing," "lifelong process" (Orozco et al., 2014, pp.14-17). It is an important form of professional development for the music therapy profession. Different types of multicultural experiential learning that the author has participated in will be discussed.

\section{Multicultural Competencies and Requirements of Music Therapy Associations}

The American Music Therapy Association, the Canadian Music Therapy Association, the Australian Music Therapy Association, and the British Association for Music Therapy have adopted ethical and professional requirements for music therapists concerning multicultural issues (American Music Therapy Association, 2013; American Music Therapy Association, 2014; American Music Therapy Association, 2015; Australian Music Therapy Association, 2014; British Association for Music Therapy, 2008; Kerr \& Sergeant, 2002). The American Music Therapy Association's Code of Ethics states, "The MT will not discriminate in relationships with clients/students/research subjects because of race, ethnicity, language, religion, marital status, gender, gender identity or expression, sexual orientation, age, ability, socioeconomic status or political affiliation" (2014; Mahoney, 2015). The term discrimination is also utilized in the Australian Music Therapy Association's Code of Ethics (2014). Although the association takes important advances toward multicultural inclusion, it needs to address the importance of cultural identity exploration in various contexts and how to find meaning in them (Australian Music Therapy Association, 2014; Swamy, 2014). A music therapist with little multicultural training may be unaware of their discrimination and bias toward certain groups. Then, the music therapist is unable to uphold the ethical code. The Code of Ethics by the Canadian Association of Music Therapy emphasizes this self-exploration. It states, music therapists will "evaluate how their experience, attitudes, culture, beliefs, values, social context, individual differences, and stresses influence their interaction with others, and integrate this awareness into all efforts to benefit and not harm others" (Kerr \& Sergeant, 2002, p. 11).

Music therapists are ethically responsible to meet professional competencies and encouraged to work toward advanced competency. The Advanced Competencies of the 
American Music Therapy Association (2015) address the music therapists' self-awareness, insight, and cultural identity. The British Association for Music Therapy (2008) also emphasizes self-awareness, but focuses instead on not letting the music therapists' views affect their treatment of clients. These are progressive, but they lack the words previously described in the Canadian Music Therapy Association's Code of Ethics (Kerr \& Sergeant, 2002).

Professional organizations, such as the European Music Therapy Confederation (2005) encourage professional development. Multicultural experiential learning has the potential as a professional development tool and can assist music therapists and trainees to develop and ensure professional competencies, advanced competencies, and abide by the Code of Ethics (American Music Therapy Association, 2014). Multicultural experiential learning may be new to the profession, but multicultural understanding and training were discussed as far back as 1967 in Iverson's (1967) prose for a multidisciplinary approach following the writings of helping professionals who worked with minorities in mental health. In order for music therapy professionals to develop multicultural skills, associations must change and adapt their Code of Ethics to reflect current literature. Then, music therapists may begin to address the "self" and multicultural training (Mahoney, 2015).

\section{Multicultural Learning is a Process}

Multicultural learning is process-oriented rather than outcome-oriented through an ongoing process (Bruscia, 2011; Orozco et al., 2014; Ratts \& Pederson, 2014; Sue, Arrendodo, \& McDavis, 1992). To become competent in multicultural skills, counseling, psychology, and higher education researchers believed that a three-part process was necessary (Orozco et al., 2014; Ratts \& Pederson, 2014; Sue et al., 1992). In the first step, they discussed the importance of the therapist becoming self-aware of their cultural identity. They also believed it was important to understand the societal structure as it exists for their cultural identity. The second step was to learn about other cultures, which we often learn about in world music. This can include different types of music and instruments used in various cultures, but also the role of music within cultures. For instance, Bradt (1997) talked about the importance of music in healing and communicating with the dead in the Xhosa community in South Africa. The final step discussed the importance of learning skills to work with individuals of different cultures. These can include music experiences, techniques, and other practices to be inclusive of culture (Hadley \& Norris, 2016).

\section{Examination of the Self}

While a sequential step process is outlined above, multicultural training needs to be non-sequential. Instead of thinking about it linearly or in a sequence, music therapists need to be responsible in revisiting these aspects of multicultural training. As humans we constantly grow and change, and so understanding the self needs to be revisited often. I think the same changing nature of societal structures and cultures also need to be considered in this way as well, especially with the consideration of globalization (Swamy, 2014). In fact, Ratts and Pederson (2014) discussed further about the influence that globalization has on multicultural competency. They focused on global context and technology, such as the internet and social media. We can now connect to people in other regions of the world within a matter of minutes or seconds.

While our culture is a reflection of our global context, it is also within each of us (Ratts \& Pederson, 2014). Today, more emphasis must be placed on the "self-examination" of the therapist and their multicultural identity that includes race, class, ethnicity, ability, religion, gender, and sexual orientation (Mahoney, 2015, p. 1). The self is created from these multiple identities and each identity intersects with another creating what we call intersectionality (Hadley, 2013). Intersectionality goes against the neo-colonial music therapy idea of homogenous groups and that individuals are the same within one identity (Comte, 2016). 
It is within this examination of ourselves that we begin to have a new awareness for multicultural competency (Ratts \& Pederson, 2014). Training of music therapy students at the institutional level may only inform them about other cultures with no reference to their own. From this, students may face difficulty developing effective experiences for their clients or advanced competency. The connection between coursework and cultural identity may not be realized in order to translate to the music therapy session. Because music therapists may have only one session with someone from a different culture, it is important that the music therapist understand their cultural identity in order to develop rapid rapport (Donley, 2017; Orozco et al., 2014). Otherwise, the opportunity for a second session is diminished.

Music therapists also need to examine their race and views on race to learn how they contribute to the therapeutic relationship (Mahoney, 2015). According to Bryson (2016) and Tatum (2003), when students are given an opportunity to describe their identity, White students will name other identifiers that do not involve race. This is different from minority students. White people are given safety and comfort in our society unlike minority groups (Yancy, 2015). Self-exploration of White privilege is a continuous process, and the music therapy field could benefit from this exploration (Hadley, 2013; Hadley \& Norris, 2016). Music therapists may experience a relearning or reexamining of values and beliefs that have attributed to their cultural identity, interactions with others, and interactions with their environment (Hadley \& Norris, 2016; Yancy, 2015). The process can be mentally, emotionally, and physically exhausting. Music therapists may argue that this process is unnecessary, "if music therapists practice empathically and sensitively" (Brown, 2002, p. 1). As we encourage our clients to move towards change, we also need to move in a similar direction despite any discomfort involved (Arredondo, 1994). Development requires change, and "change is core to our professional work" (1994, p. 308-309).

\section{Learning about Other Cultures}

The music therapy community likely feels most confident in this area of multicultural training. In a survey study by Darrow and Molloy (1998), 75 percent of music therapists indicated they knew multicultural music generally and in relation to their clients. It is uncertain how music therapy students and professionals learn about cultures and their music in the university setting in the United States, Australia, and other schools internationally, such as in Norway. Each country has different accreditation methods for its music therapy degree programs (Australian Music Therapy Association, 2012; Darrow \& Molloy, 1998; European Consortium for Art Therapies Education, 2017). Some may offer more flexibility within the curriculum (Australian Music Therapy Association, 2012).

Previously, some claimed "a music therapist's university education cannot be considered complete without a required course in world music or ethnomusicology," (Moreno, 1988, p. 20) but now multicultural counseling also needs to be considered (Bradt, 1997; Darrow \& Molloy, 1998; Toppozada, 1995). Already, music therapy students are required to complete extensive coursework, and music therapy faculty struggle for a lack of personnel or their experience in teaching multicultural topics (Toppozada, 1995). Internationally, some music therapy programs stated that multicultural issues were not currently significant in the field (Brown, 2002). International travel can also be fruitful to learn about one's worldview, other cultures, and multicultural issues. Local cultural events can also be considered (Swamy, 2014).

\section{Developing Clinical Skills}

\section{Listening to Client Issues}

In order to develop clinical skills with diverse cultures, music therapists need to listen to client issues to understand what the client or group of clients face as a minority within societal constructs. Mahoney (2015) discussed this as it relates to the LGBTQIA 
community and individuals with disabilities. Andrew Lightstone focused on listening first with a client in the First Nations community in Ontario (Lightstone \& Hadley, 2013). Instead of instructing his client, he created a space for her to be heard as she found her voice through her native music.

Therapists may need to include an interpreter (Ratts \& Pederson, 2014). This allows the client to express themselves in their native language when the English translation or interpretation is not as meaningful. Schwantes (2015) wrote about utilizing an interpreter in music therapy. When an interpreter was unable to attend, Schwantes said that communicating and facilitating musical experiences became more difficult. Through the complex web of communication, music therapists can overlook significant words or statements spoken by their clients. Getano Bann used a different approach by listening and observing clients (Bann \& Hadley, 2013). He listened for silence, read body language of clients, and remained present with the energy in the space.

\section{Client Interaction}

Today, we interact with more diverse individuals (Brown, 2002). Societies are becoming more multicultural and diverse (Bradt, 1997). We may find that our relationships with our clients develop more in depth with those with whom we share similar cultural identities (Hadley, 2013). Lightstone talked about his experience at a youth camp for children who were disadvantaged (Lightstone \& Hadley, 2013). Although Lightstone had developed great relationships with the campers, his colleague had a similar background to the participants, and therefore, a deeper connection with them. While this may be true for this scenario, music therapists must consider each case as unique. Encouraging the client to teach the music therapist music about their culture may support the development and preservation of the therapeutic relationship.

\section{Developing Skills}

There are three types of skills for music therapists to learn when developing multicultural competency (Brown, 2002). First, the music therapist develops communication skills that are culturally appropriate and empathetic. Secondly, clinicians utilize music therapy interventions appropriate to the context and culture of the client. This includes the understanding and importance of musical instruments in cultures. The third involves the therapist learning and advocating for clients (Stige, 2004). The music therapist becomes an activist for their client and supports the integrity of the therapeutic relationship.

\section{Importance of Multicultural Experiential Learning}

When considering these areas in multicultural learning and training, there seems to be a gap between learning about cultures in informal and formal learning environments and the development of those clinical skills (Moreno, 1988). This may be especially true for music therapists who are trained and practice in rural environments (Brown, 2002). After completion of coursework and requirements for accreditation, the responsibility for multicultural learning falls on the music therapist (Toppozada, 1995).

\section{Multicultural Experiential Learning Defined}

For this paper, multicultural experiential learning will be defined as the obtainment of knowledge about multicultural identities and the people within them through experiences within the self or between the self and other that goes beyond conventional classroom learning (Bateson, 2000). This type of learning must occur outside the formal classroom and in informal learning environments in order to generalize classroom and professional development knowledge to the community and clinical space. Multicultural experiential learning is expected to occur for a brief period of time as opposed to cultural immersion in a foreign context abroad. 


\section{Overview of Multicultural Experiential Learning}

According to Kolb (2014), the founder of experiential learning theory, experiential learning has been defined in many ways making the meaning unclear and ambiguous to researchers and educators. Fenwick (2000) believed that this ambiguity surrounding the definition was due to the difficulty in separating the term from formal education practice. Among its many definitions, experiential learning has been defined as "a particular form of learning from life experience; often contrasted with lecture and classroom learning" (2014, para. 2). Kolb understood experiential learning differently as a holistic process that one could use to relate to all aspects of their life. While it is possible to view experiential learning as occurring in formal and informal learning environments, I want to focus on experiential learning as it includes informal learning environments. Currently, the literature about multicultural experiential learning is lacking in music therapy and few in other professions, such as counseling.

Arthur and Achenbach (2002; Achenbach \& Arthur, 2002) explored the impact of experiential learning in cross-cultural training, counseling, and their multicultural counseling curriculum. One of the experiential learning exercises they discussed was BAFA BAFA, which explores culture shock (Arthur \& Achenbach, 2002). In BAFA BAFA, students are separated into two groups that represent two imaginary cultures (Bruschke, Gartner, \& Seiter, 1993; Gannon \& Poon, 1997). Each group is given information about the culture they role-play. After engaging with members from their cultural group, members are asked to exchange cultural ideas with the second group. Two studies on BAFA BAFA found strikingly different results. Bruschke et al. (1993) found that BAFA BAFA encouraged ethnocentrism in students while Gannon and Poon (1997) found that the experience heightened students' multicultural awareness. Arthur and Achenbach (2002) also mentioned a second experiential tool and card game called Barnga, which is "designed to reflect cultural clashes and communication barriers that occur in real life situations" (p. 3; Steinwachs, 1990). Achenbach and Arthur (2002) utilized Barnga to study how experiential learning affected students' multicultural awareness, the students' process of multicultural learning, the translation of experiential learning to counseling practice, and its potential to improve the university curriculum in counseling programs. Like BAFA BAFA, Barnga gives students the opportunity to learn about culture shock. Students in the experience assume that everyone is playing using the same instructions, but the instructions vary slightly among participants. Through the varying rules, students learn to navigate different cultural dynamics. Using grounded theory, Achenbach and Arthur recruited and retained 19 participants over the three stages of the study: the simulation exercise, individual interviews, and focus groups. Three cultural schemas were identified in the results including the cultural condition or environment, cultural other, and cultural self, which were found to promote student understanding and growth in cultural empathy.

Kim and Lyons (2003) discussed experiential learning in multicultural counseling with a greater emphasis on games and gaming. These games included Multicultural Jeopardy; Cultural Bingo; and Step Forward, Step Back. In Step Forward, Step Back, students are asked to move forward or back according to their responses to statements about privilege (Kim \& Lyons, 2003). In this experience, students are given a piece of paper with a cultural identity different from their own, and their responses are based on this cultural identity. Students may also respond based on their own cultural identity. More recently, Step Forward, Step Back has been known as a Privilege Walk (Ngoasheng \& Gachago, 2017). Teachers may modify the Privilege Walk in multiple ways. The teachers can direct statements about cultural identity or the students' cultural identity. Instead of moving forward and backward, teachers can also instruct students to move only forward or only backward. These experiences assist students in seeing privilege and disadvantages from their own and others' perspectives. They are especially powerful. Students may feel guilt or shame as their privilege and disadvantages are vividly brought to the forefront. Aspects of these experiences, such as the size of the steps taken can lead students to new awareness and understanding. In an- 
other example of experiential learning, indirect care staff at a hospital participated as a patient in the hospital for a day to better understand inpatient experiences (Arthur \& Achenbach, 2002). Direct care staff and indirect care staff had mixed reviews about the experience. Direct care staff held more negative views while observing others participate, and indirect staff that participated felt they benefited from the experience.

Role-playing may be important for learning and professional development, such as in supervision, but,role-playing a cultural group or population must be avoided (Stige, 2001). Role-playing a group or population may encourage oppression toward groups that the neo-colonial music therapist labels as homogenous (Comte, 2016). Although experiential learning may offer benefits to its participants, faculty need to carefully and cautiously incorporate this tool into the university curriculum. Firstly, educators need to understand how experiential learning meets the training needs of participants (Arthur \& Achenbach, 2002). Educators also need to create safe spaces for participants to identify and explore thoughts and emotions. For these reasons and based on my previous experience with experiential learning, I think the examples below align more closely with this paper's ideas of multicultural experiential learning and the music therapy profession.

The music therapy field and clients of music therapists will continue to benefit from music therapists' professional development in multicultural competence as long as music therapists continue to pursue those opportunities. According to Arthur and Achenbach (2002), students who discontinued practice in multicultural competence were more likely to regress to their innate cultural beliefs. Students and professionals need to have a strong initiative to continue their practice in multicultural training and learning. Multicultural learning experiences may open possibilities for music therapists in the majority in any context to gain understanding about the perspectives of minorities.

\section{Multicultural Experiential Learning in Music Therapy}

At this time, there are only a few articles about experiential learning in the music therapy literature (Dileo, 2000; Langdon, 2001; Lindvang, 2013; Murphy, 2007; Murphy \& Wheeler, 2005; Wigram, 1996). None of these mentions experiential learning theory in conjunction with multicultural issues (Dileo, 2000). Instead, they focus on music therapy training overall and personal therapy and self-care (Langdon, 2001 ; Lindvang, 2013 ; Murphy, 2007 ; Murphy \& Wheeler, 2005 ; Wigram, 1996).

Faculty may implement a holistic approach, as described by Kolb (2014), throughout the curriculum for students. A professional trained in multicultural counseling would be ideal since they have participated in group processes and may also have experience in leading groups towards this skill set. A faculty member with training in world music or ethnic studies may lack this skill for facilitating difficult dialogues. Faculty members with limited experience need to seek guidance and collaboration with other members at their institutions. Faculty members may not feel qualified to implement this in their programs alone (Toppozada, 1995).

Beyond graduation, interns and early career professionals can be subjected to multicultural learning in combination with other client needs at internship and during clinical training. While these formal settings can include multicultural experiences, they lack an opportunity for isolated acquisition of these skills. Isolated learning concentrates on one application at a time and simplifies the process. Music therapists must consider the importance of learning these skills alone before integrating them into music therapy practice. For example, a great musician and music therapist often practices their music by isolating the voice, guitar, piano, etc., before integrating instruments together. In this same way, the music therapist must isolate multicultural learning from their clinical work in order to proceed toward multicultural competence.

\section{Multicultural Discoveries of a White Music Therapist}

In this section, I share insight into my process of multicultural experiential learning while participating in a multicultural counseling course during my graduate program. 
Specifically, I want to talk about how my experiences have impacted me. I hope to be vulnerable about my realization of "White innocence" (Yancy, 2015, par. 8) in my life and to encourage others to look at the racism, prejudices, and judgments they have made toward people they have oppressed.

\section{About the Author}

I am a White female Christian cisgender heterosexual abled-bodied music therapist who grew up in Shreveport, Louisiana. Financially, I felt comfortable and at ease with what my White parents were able to provide. I earned an undergraduate degree in Music Performance at the University of Louisiana at Monroe, and my graduate degree in Music Therapy from Appalachian State University. I consider myself fierce, blunt, honest, and resilient about multicultural issues in the field of music therapy.

\section{My Process}

Appalachian State University is in rural Boone, North Carolina. In the 2016 American Community Survey, $92.9 \%$ of the population was White according to the United States Census Bureau (2016). (2016). Blacks and African Americans consisted of 2.3\%, Hispanics and Latinos 2.6\%, American Indians $0.5 \%$, and Asians $1.5 \%$ of the population there. The lack of diversity was shocking in Boone. I remember describing my new community as a utopia as depicted in Lost Horizon, because of the low crime rate. Unconsciously and regrettably, I associated this low crime rate with a lack of diversity based on my prejudice towards Blacks that I learned from my family, friends, and the media.

Despite these statistics, there was a good representation of individuals in my class who identified within various races, genders, and sexual orientations. This included my professor, a Black male. With his instruction, I began to challenge and unlearn my racism, prejudices, and judgments of Black people and other minority groups. While discussion with a diverse group of peers was an important part of the course, I felt unhinged and anxious about the tasks ${ }^{1}$ presented to us by my professor. I often sat numb hoping my professor would reveal how to complete the assignments. I was certain that the best result was to reach the outcome without moving through the process. It took a lot of courage to enter this process, for each task where it seemed all new and unmapped territory. Each task focused on a division of identity including socioeconomic status, gender, sexual orientation, and religion. In the process, I was most surprised by my family's covert communication to construct barriers to change. My beliefs on multicultural issues were shifting, but my family and friends' beliefs on the same issues remained the same.

\section{Socioeconomic status}

In the United States, the Health and Human Services department offers assistance for eligible individuals and families based on their income. The expenses covered include groceries, heating and cooling, and other living costs (U. S. Department of Health and Human Services, 2015). According to a report from the U.S. Census Bureau by Irving and Loveless (2015), in 2012, 21.3 percent of the U.S. population or 52.2 million people received assistance each month. My knowledge about social services was limited to food stamps, which assist with food costs through the Supplemental Nutrition Assistance Program (SNAP). I held a negative impression, because I heard about the abuse of this program. I began to acquaint social services with shame as a result.

For the first experiential experience, I was required to obtain a public assistance application without using online or digital resources. This was designed to simulate what individuals in poverty may experience without access to online resources. This process supported my multicultural learning, because talking to people about my need for help facilitated my understanding of shame around the cultural division of poverty. Shame appeared in my experience in a different way. I had planned to ask city employees in 
local offices for help, but they were closed. Instead, a man downtown helped me locate the building, because he had received public assistance in the past. He initiated conversation with me and asked me for money. Sadly, I admit he would have remained invisible to me otherwise. After our talk, I felt ashamed, disgusted, and guilty becoming aware of my hidden agenda. Completing the task was now easy. From the experience, I have a greater awareness of my prejudices towards individuals who are impoverished. This has encouraged me to recognize the false beliefs I have and to change my interactions with this demographic. This small experience has helped me gain empathy for people within this division of culture.

\section{Sexual orientation}

I first became aware of sexual orientation in secondary school where there was greater acceptance of individuals who identified as LGBTQ. A few of my friends were LGBTQ, but I never felt comfortable when they displayed affection with partners. In my multicultural counseling class, I was introduced to the Gender Unicorn (Trans Student Educational Resources, 2017). This image illustrates the complexity of gender identity and sexual orientation. Initially, this was hard to process, but it helped me to understand my identity within this dimension. I had greater emotional attraction with women, but I was physically attracted to men. Because I was confused about this awareness, I created boundaries, abstained from physical touch with women that was beyond a hug, and displayed homophobic behavior.

For this next task, we were encouraged to display three behaviors in public that suggested we were of a different sexual orientation than how we identified. I chose to ask a female friend to help me, because I was aware of my homophobia. I felt uncomfortable, vulnerable, and paranoid during the experience. I worried about assumptions and judgment from others. It was also difficult to participate in the task because I knew that it was not my truth. While I was worried about the thoughts of other people, I learned from one classmate that they were concerned about their safety. My concerns seemed trivial, and my understanding shifted, because I have never feared for my safety when I was with a partner. I felt like a coward, and these individuals and couples seemed to grow in boldness and courage. The experience gave me a new confidence in my sexual orientation and gave me an opportunity to explore potential thoughts and feelings of individuals who feel unsafe and are scrutinized for their cultural identities. Because I am a cisgender heterosexual female, I am not questioned when I display physical attraction with men or emotional attraction with women. On a later date, I observed a same-sex couple holding hands. There was a presence of strength and an abundance of love.

\section{Religion}

In Boone, there is one Jewish temple, many Christian churches, and two Muslim mosques an hour away. I previously lived in Morganton, North Carolina where I attended a prayer. It surprised me there was a Muslim mosque in this small city of the Bible Belt which is a grossly populated area of Southern Baptists, Methodists, and evangelical Christians that spans from Virginia, down to Florida, and West to Texas (Rosenberg, 2017).

I was not familiar with the proper clothing to wear to a prayer other than maybe a hijab. After completing a preliminary search on the mosque's website, I chose to not wear one, and I wore a long dress that covered my shoulders and sandals instead. I was nervous to attend, because I worried about what people thought. Also, I did not know the ritual and procedures during the prayer. It was necessary for me to follow my instincts, ask questions, and follow instructions. A clear divide was evident for spaces for different genders with men in the front and women in the back. This seemed strange to me, but I felt comforted when a man began talking about women's rights. As he advocated for women, I felt my nervousness and anxiety melt away. 
Two women sat in the women's section with me. One went to a shelf to retrieve a golden hijab in exchange for the black hijab on her head. I watched this ritual in wonder. The second woman came towards me and extended her arms for a light handshake. This action of invitation warmed my spirit. After the prayer, I had planned to quickly retreat home. Instead, a man asked, "Do you have any questions?" and I stopped. Together two men and I exchanged dialogue about Islam, Christianity, and hardships they faced. It was difficult to hear their fear and the repercussions of speaking in public about Islam. Hearing about their experiences and learning about Islam exposed the false messages delivered by the national media. This information demystified the stereotype and association of terrorists and the Islam religion, and I felt more equipped and encouraged to advocate for them in the future.

\section{Reflecting on Experiences as a Minority (at the Micro and Macro levels)}

Until my multicultural counseling and systemic multicultural counseling courses, I never considered my identity in context. In context where I was the minority, I found it difficult to be authentic. I felt agitated, because I was fighting to find myself in a new environment with different conditions. These feelings that I rarely experience as a White woman may help me understand and empathize with minorities.

\section{The Chinese Music Therapy Network}

At the American Music Therapy Association national conference in Sandusky, OH, I attended the Chinese Music Therapy Network meeting. I was interested in connecting with music therapy students and music therapists in this group to learn more about their culture. I was nervous and searched for courage as I joined the meeting. I did not want to be perceived as a White person who wants to be Asian as discussed in the YouTube video titled, "The Egg: White Person Who Acts Asian" (Off the Great Wall, 2013). A guest speaker and I were the minority, but only in this small context. If we exited the room, we were able to return to a context where we were again in the majority. I was thankful that the women were welcoming and kind, and I felt comforted as a member of the gender majority. The meeting organizer thoughtfully informed me that the group would be speaking in Mandarin. I was only a beginner Mandarin speaker at the time, but I chose to stay and listen. I was able to follow some of the discussion by watching gestures, facial expressions, and listening for English words.

\section{Classroom Minority}

I also took a second multicultural counseling class called systemic multicultural counseling when I first discovered that I was a minority within a micro context at my school. I was the only music therapy major in a course with marriage and family therapy and counseling majors. This challenged me, and discussions often included theories and models that were not introduced in my music therapy classes. My professor and classmates also held different orientations and perspectives on therapy. Although the classroom environment felt inviting, I thought that my contribution to the discussion would automatically be considered wrong. I questioned how I could contribute to the course.

In my music therapy classes, my behavior was different in class discussion. Everyone in my music therapy graduate courses was White and mostly female. I was always in the majority on campus and in music therapy classes. As a minority major in the multicultural counseling course, I wanted to fit in with my peers, and my behavior shifted. I became fearful and anxious before speaking. Upon this realization, I was able to process and reflect why I thought and behaved the way I did in that setting. This helped me to reestablish my identity and encouraged me to exhibit my truth. 


\section{Conclusion}

The field of music therapy has encouraged music therapists to explore multicultural learning through professional development programs and by amending the professional and advanced competencies (American Music Therapy Association, 2013; American Music Therapy Association, 2015). University curriculums are also evolving to help prepare students for these competencies (American Music Therapy Association, 2013; American Music Therapy Association, 2015; Mahoney, 2015; Music Therapy at Temple University, n.d.; University of Limerick, n.d.; Victoria University of Wellington, n.d.). Outside university and professional development settings, music therapists must continue to address multicultural competence, which is a life-long process. During this process, mistakes are necessary and cultural humility must put into action multicultural learners at all levels (Whitehead-Pleaux \& Tan, 2017).

To grow as a profession in multicultural competence, we need to find ways to understand perspectives of minorities and marginalized groups through an insider's perspective (Stige, 2002). The three-part process of examining the self, learning about other cultures, and developing clinical skills discussed by several researchers must become a non-sequential process that includes multicultural experiential learning (Orozco et al., 2014; Ratts \& Pederson, 2014; Sue, Arrendodo, \& McDavis, 1992). Multicultural experiential learning offers music therapists the ability to practice skills in informal environments, which are isolated and separate from the clinical space. Through this learning, music therapists are able to explore their intersectionality within each dimension of culture generating a wide knowledge, understanding, and awareness of multiculturalism, especially as it relates to the self (Bateson, 2000). The examples of multicultural experiential learning may be beneficial for music therapists and students, but individuals must exert caution in their implementation. Individuals with experience in multicultural counseling and group processing would be the best candidates to facilitate these types of experiences. From the narratives above, these experiences show potential to improve multicultural learning and competence in music therapy and other helping professions.

\section{Notes}

1. The tasks for the multicultural counseling course were originally an assignment by Dr. Mona Mittal, a former professor of my professor, Dr. Nickolas Jordan. He told me that he modified and added new "wrinkles" when making them a part of his coursework.

\section{References}

10th European Music Therapy Conference. (2016). A symphony of dialogues. Retrieved from http://www.emtc2016.at/\#contact

Achenbach, K., \& Arthur, N. (2002). Experiential learning: Bridging theory to practice in multicultural counseling. Guidance and Counseling, 17(2), 39-45.

American Music Therapy Association. (2013). Professional competencies. Retrieved from http://www.musictherapy.org/about/competencies/

American Music Therapy Association. (2014). Code of ethics. Retrieved from http://www.musictherapy.org/about/ethics/

American Music Therapy Association. (2015). American music therapy association advanced competencies. Retrieved from http://www.musictherapy.org/members/advancedcomp/

American Music Therapy Association. (2016). 2016 annual music therapy conference. Retrieved from https://www.musictherapy.org/assets/1/7/2016ConfProgram_final.pdf

American Music Therapy Association. (2017a). AMTA 2017 conference, A mindful approach to music therapy. Retrieved from https://www.musictherapy.org/events/ amta_2017_conference_a_mindful_approach_music_therapy/

American Music Therapy Association. (2017b). Standards for education and clinical training. Retrieved from https://www.musictherapy.org/members/edctstan/ 
American Music Therapy Association. (2018). AMTA 2018 conference. Retrieved from https://www.musictherapy.org/events/amta_2018_conference/

Arredondo, P. (1994). Multicultural training: A response. Counseling Psychologist, 22(2), 308-314, http://dx.doi.org/10.1177/0011000094222005.

Arthur, N., \& Achenbach, K. (2002). Developing multicultural counseling competencies through experiential learning. Counselor Education and Supervision, 42(1), 2-14, https://dx.doi.org/10.1002/j.1556-6978.2002.tb01299.x.

Australian Music Therapy Association. (2012). How to become a RMT. Retrieved from http://www.austmta.org.au/about/how-to-become-a-rmt

Australian Music Therapy Association. (2014). Code of ethics. Retrieved from http://www.austmta.org.au/system/files/Code\%20of\%20Ethics\%202014.pdf

Bann, G., \& Hadley, S. (2013). The view from the floor. In S. Hadley (Ed.), Experiencing race as a music therapist: Personal narratives (pp. 63-75). Gilsum, NH: Barcelona Publishers.

Bateson, G. (2000). Steps to an ecology of mind. Chicago, IL: University of Chicago Press.

Bradt, J. (1997). Ethical issues in multicultural counseling: Implications for the field of music therapy. The Arts in Psychotherapy, 24, 137-143, https://doi.org/10.1016/ S0197-4556(97)00017-8.

British Association for Music Therapy. (2008). Guide to professional practice. Retrieved from http://www.hpc-uk.org/assets/documents/10002367FINALcopyofSCPEJuly2008.pdf

Brown, J. M. (2002). Towards a culturally centered music therapy practice. Voices: A World Forum for Music Therapy, 2(1), https://www.voices.no/index.php/voices/article/view/72.

Bruscia, K. E. (2011). Ways of thinking in music therapy. AMTA's 2011 Sear's Distinguished Lecture Series, http://amtapro.musictherapy.org/?p=797.

Bruschke, J. C., Gartner, C., \& Seiter, J. S. (1993). Students' ethnocentrism, dogmaticism, and motivation: A study of BAFA BAFA. Simulation \& Gaming, 24, 9-20, https://doi.org/ 10.1177/1046878193241003.

Bryson, B. (2016). Social justice, race, and racism in social service programs. Boone, NC, Presentation.

Comte, R. (2016). Neo-colonialism in music therapy: A critical interpretive synthesis of the literature concerning music therapy practice with refugees. Voices: A World Forum for Music Therapy, 16(3), https://voices.no/index.php/voices/article/view/865/735.

Darrow, A. A., \& Molloy, D. (1998). Multicultural perspectives in music therapy: An examination of the literature, educational curricula, and clinical practices in culturally diverse cities of the United States. Music Therapy Perspectives, 16, 27-32, https://doi.org/ 10.1093/mtp/16.1.27.

Dileo, C. (2002). Ethical thinking in music therapy. Cherry Hill, NJ: Jeffrey Books.

Donley, J. (2017). Understanding how Western-trained music therapists in China incorporate Chinese culture in their sessions: An ethnographic study. Boone, NC: Appalachian State University. Unpublished master's thesis.

European Consortium for Arts Therapies Education. (2017). Norway: Résumé of the professional and educational contexts of the arts therapies. Retrieved from http://www.ecarte.info/ membership/directory/norway.htm

European Music Therapy Confederation. (2005). Ethical codes. Retrieved from http://www.emtc-eu.com/ethical-code/

Fenwick, T. (2000). Expanding conceptions of experiential learning: A review of five contemporary perspectives on cognition. Adult Education Quarterly, 50(4), 243-272, https://doi.org/10.1177/07417130022087035.

Gannon, M. J., \& Poon, J. M. (1997). Effects of alternative instructional approaches on crosscultural training outcomes. International Journal of International Relations, 21, 429-446, https://doi.org/10.1016/S0147-1767(96)00035-1.

Hadley, S. (2013). Experiencing race as a music therapist: Personal narratives. Gilsum, NH: Barcelona. 
Hadley, S., \& Norris, M. S. (2016). Musical multicultural competency in music therapy: The first step. Music Therapy Perspectives, 34, 129-137, https://doi.org/10.1093/mtp/miv045.

Irving, S. K., \& Loveless, T. A. (2015). Dynamics of economic well being: Participation in government programs, 2009-2012: Who gets assistance? Retrieved from https://www.census.gov/content/dam/Census/library/publications/2015/demo/ p70-141.pdf

Iverson, L. F. (1967). The necessity for a multidisciplinary approach to music therapy. Journal of Music Therapy, 4, 106-107, https://doi.org/10.1093/jmt/4.3.106.

Kerr, T., \& Sergeant, J. A. (2002). Code of ethics. Retrieved from http://www.musictherapy.ca/ wp-content/uploads/2016/04/codeofethics99.pdf.

Kim, B. S. K., \& Lyons, H. Z. (2003). Experiential activities and multicultural counseling competence training. Journal of Counseling and Development, 81(4), 400-408, https://dx.doi.org/10.1002/j.1556-6678.2003.tb00266.x.

Kolb, D. A. (2014). Experiential learning: Experience as the source of learning and development (2nd ed.). Upper Saddle River, NJ: Pearson Education.

Langdon, G. S. (2001). Experiential music therapy group as a method of professional supervision. In M. Forinash (Ed.), Music therapy supervision (pp. 211-217). Gilsum, NH: Barcelona Publishers.

Lightstone, A., \& Hadley, S. (2013). Reflections on the complexities and paradoxes of identity. In S. Hadley (Ed.), Experiencing race as a music therapist: Personal narratives (pp. 29-41). Gilsum, NH: Barcelona Publishers.

Lindvang, C. (2013). Resonant learning: A qualitative inquiry into music therapy students' experiential learning processes. Qualitative Inquiries in Music Therapy, 8, 1-30.

Mahoney, E. R. (2015). Multicultural music therapy: An exploration. Voices: A World Forum for Music Therapy, 15(2), https://www.voices.no/index.php/voices/article/view/844.

Mid-Atlantic Region of the Music Therapy Association. (2017). 2017 regional conference preliminary program. Retrieved from http://mar-amta.org/wp-content/uploads/2015/02/ 2017MAR-AMTAConferenceCMTESlate.pdf

Moreno, J. (1988). Multicultural music therapy: The world music connection. Journal of Music Therapy, 25, 17-27, https://doi.org/10.1093/jmt/25.1.17.

Murphy, K. (2007). Experiential learning in music therapy: Faculty and student perspectives. Qualitative Inquiries in Music Therapy, 3, 31-61.

Murphy, K., \& Wheeler, B. (2005). Symposium on experiential learning in music therapy report of the symposium sponsored by the World Federation of Music Therapy Commission on Education, Training, and Accreditation. Music Therapy Perspectives, 23, 138-143, https://doi.org/10.1093/mtp/23.2.138.

Music Therapy at Temple University. (n.d.) MMT. Retrieved from https://sites.temple.edu/ musictherapy/mmt/

Ngoasheng, A., \& Gachago, D. (2017). Dreaming up a new grid: Two lecturers' reflections on challenging traditional notions of identity and privilege in a South African classroom. Education as Change, 21(2), 187-207, https://doi.org/10.17159/1947-9417/2017/2479.

Off the Great Wall. (2013). The egg: White person who acts Asian. Retrieved from https://www.youtube.com/watch?v=-9AFM77JYig

Orozco, G., Lee, W., Blando, J., \& Shooshani, B. (2014). Introduction to multicultural counseling for helping professionals (3rd ed.). New York: Routledge.

Ratts, M. J., \& Pederson, P. B. (2014). Counseling for multiculturalism and social justice: Integration, theory, and application (4th ed.). Alexandria, VA: American Counseling Association.

Rosenberg, M. (2017). The Bible belt in the United States. Retrieved from https://www.thoughtco.com/the-bible-belt-1434529. 
Schwantes, M. (2015). Choosing the right interpreter: Reflections on my experience. Voices: A World Forum for Music Therapy, 15(2), https://www.voices.no/index.php/voices/article/ view/820.

Slippery Rock University. (n.d.). Music therapy: Master of music therapy. Retrieved from http://www.sru.edu/academics/graduate-programs/music-therapy-(master-of-musictherapy)

Steinwachs, B. (1990). Barnga: A simulation game on cultural clashes. Yarmouth, ME: Intercultural Press.

Stige, B. (2001). The fostering of not-knowing barefoot supervisors. In M. Forinash (Ed.), Music therapy supervision (pp. 161-177). Gilsum, NH: Barcelona Publishers.

Stige, B. (2002). Culture-centered music therapy. Gilsum, NH: Barcelona Publishers.

Stige, B. (2004). Feminists, postcolonialists, and other music therapists. Voices: A World Forum for Music Therapy, 4(3), https://voices.no/index.php/voices/article/view/184/143.

Sue, D. W., Arredondo, P., \& McDavis, R. (1992). Multicultural counseling competencies and standards: A call to the profession. Journal of Counseling \& Development, 70, 477-486, https://dx.doi.org/10.1002/j.1556-6676.1992.tb01642.x.

Swamy, S. (2014). Music therapy in the global age: Three keys to successful culturally centered practice. New Zealand Journal of Music Therapy, 12, 34-57.

Tatum, B. D. (2003). "Why are all the Black kids sitting together in the cafeteria?": And other conversations about race. New York, NY: BasicBooks.

The World Federation of Music Therapy. (2017a). Cultural program. Retrieved from http://www.jmta.jp/world/music_15/ja/timetable/pdf/culturalprograms.pdf

The World Federation of Music Therapy. (2017b). List of presentations. Retrieved from http://www.jmta.jp/world/music_15/ja/timetable/pdf/presentations.pdf

Toppozada, M. R. (1995). Multicultural training for music therapists: An examination of current issues based on a national survey of professional music therapists. Journal of Music Therapy, 32, 65-90.

Trans Student Education Resources. (2017). The gender unicorn. Retrieved from http://www.transstudent.org/gender

United States Census Bureau. (2016). Quickfacts: Boone, NC. Retrieved from https://www.census.gov/quickfacts/table/INC110215/3707080\#flag-js-X

United States Department of Health and Human Services. (2015). Social services. Retrieved from https://www.hhs.gov/programs/social-services/index.html

University of Limerick. (n.d.). Irish world academy: Music therapy MA. Retrieved from http://www.ul.ie/graduateschool/course/music-therapy-ma

Victoria University of Wellington. (n.d.). World musics and music therapy. Retrieved from http://www.victoria.ac.nz/courses/nzsm/521/2017/offering?crn = 14292

Whitehead-Pleaux, A., \& Tan, X. (2017). Cultural intersections in music therapy: Music, health, and the person. Dallas, TX: Barcelona Publishers.

Wigram, T. (1996). Becoming clients: Role playing a clinical situation as an experiential technique in the training of advanced level music therapy students. In I. N. Pedersen \& L. O. Bonde (Eds.), Music therapy within multi-disciplinary teams: Proceedings of the 3rd European Music Therapy Conference, Aalborg, June, 1995. Denmark: Aalborg Universitetsforlag.

Yancy, G. (2015). Dear white America. The New York Times, Retrieved from https://opinionator.blogs.nytimes.com/2015/12/24/dear-white-america/. 